\title{
Struktur Komunitas Echinodermata di Padang Lamun Karimunjawa, Jepara Jawa Tengah
}

\author{
Hanaf Fatima*, Ria Azizah Tri Nuraini, Adi Santoso \\ Departemen IImu Kelautan, Fakultas Perikanan dan IImu Kelautan, Universitas Diponegoro \\ JI. Prof. H. Soedarto S.H, Tembalang,Semarang, Jawa Tengah 50275 Indonesia \\ ${ }^{*}$ Corresponding author, e-mail : hanaf_f@yahoo.com
}

\begin{abstract}
ABSTRAK: Pulau Kemujan dan Pulau Bengkoang Karimunjawa memiliki beberapa ekosistem, salah satunya adalah ekosistem padang lamun. Secara ekologis, padang lamun merupakan habitat bagi biota laut salah satunya Echinodermata. Echinodermata berperan sebagai salah satu komponen dalam rantai makanan, pemakan sampah organik dan hewan kecil lainnya. Tujuan dari penelitian ini adalah menganalisis struktur komunitas Echinodermata dan mengetahui kerapatan lamun. Metode struktur komunitas Echinodermata sama dengan lamun yaitu metode Seagrass Watch. Masing-masing lokasi dibagi menjadi 3 titik sekaligus sebagai pengulangan, dengan jarak antar titik 25 meter sejajar garis pantai, penarikan transek kuadran berukuran $50 \times 50 \mathrm{~cm}^{2}$ ketika pertama kali ditemukannya lamun, tegak lurus kearah laut lepas sepanjang $50 \mathrm{~m}$. Transek kuadran diletakkan dimulai dari titik, lalu ke arah 1 meter dari kanan dan 1 meter dari kiri, dengan jarak antar kuadran $5 \mathrm{~m}$. Hasil penelitian Echinodermata di Pulau Kemujan yaitu Kelas Holothuroidea dan Echinoidea, sedangkan di Pulau Bengkoang ditemukan Kelas Holothuroidea, Asteroidea dan Echinoidea. Kelimpahan Echinoidermata tertinggi di Pulau Bengkoang. Nilai indeks keanekaragaman $\left(H^{\prime}\right)$ Pulau Kemujan tergolong rendah $(0,025)$, indeks keseragaman rendah $(0,030)$ dan tidak ada yang mendominansi. Sedangkan di Pulau Bengkoang keanekaragaman $\left(H^{\prime}\right)$ tergolong sedang $(1,048)$, keseragaman $(E)$ tinggi $(0,793)$ dan tidak ada yang mendominansi. Hasil kerapatan lamun lebih tinggi di Pulau Bengkoang yaitu $164,44 \mathrm{ind} / \mathrm{m}^{2}$. Jenis substrat di kedua lokasi yaitu pasir dengan kandungan bahan organik di Pulau Kemujan tergolong rendah, sedangkan Pulau Bengkoang tergolong sedang.
\end{abstract}

Kata kunci: Echinodermata; Dominansi; Keanekaragaman; Kelimpahan; Keseragaman; Lamun

\section{Structure and Community Echinodermata on Seagrass Ecosystem in Karimunjawa Island Jepara, Central Java}

ABSTRACT: The island of Kemujan and Pulau Bengkoang Karimunjawa has several ecosystems, one of which is seagrass field ecosystem. Ecologically, seagrass land is a habitat for the sea biota of one of the Echinodermata. Echinodermata serves as one of the components in the food chain, organic waste eaters and other small animals. The aim of the study was to analyse the structure of the Echinodermata community and know the density of seagrass. The method of the community structure of Echinodermata is the same as the Seagrass Watch. Each location is divided into 3 dots at once as a repetition, with a distance between points of 25 meters parallel to the coastline, the withdrawal of transect quadrant measuring $50 \times 50 \mathrm{~cm}^{2}$ When it was first discovered seagrass, perpendicular to the sea to the end of $50 \mathrm{~m}$. The quadrant Transect is placed starting from the point, then towards 1 meter from the right and 1 meter from the left, with the distance between the Quadrant $5 \mathrm{~m}$. Research results of Echinodermata in the island of Kemujan, the Holothuroidea class and Echinoidea, while on Bengkoang Island were found the Holothuroidea class, Asteroidea and Echin The highest abundance of Echinoidermata in Bengkoang Island. The value of diversity index $(H ')$ of Kemujan Island is relatively low (0.025), low uniformity Index (0.030) and no one dominates. While in Bengkoang Island diversity $\left(H^{\prime}\right)$ classified as medium (1.048), uniformity (E) high (0.793) and no one dominates. The result of seagrass density higher in Bengkoang Island is $164.44 \mathrm{ind} / \mathrm{m}^{2}$. Type of substrate in both locations, namely sand with organic material content in the island of Kemujan relatively low, while Bengkoang Island is classified medium

Keywords: Echinodermata; dominancy; diversity; abundance; uniformity; seagrass 


\section{PENDAHULUAN}

Pulau Kemujan dan Pulau Bengkoang masuk dalam Kawasan Taman Nasional Karimunjawa berdasarkan Surat Keputusan Direktur Jendral Perlindungan Hutan dan Konservasi Alam No. SK. 79/IV/Ser. 3/2005. Pulau Kemujan memiliki sarana dermaga laut, Bandar Udara Dewandaru, PLTD, serta terdapat aktivitas penduduk, sedangkan Pulau Bengkoang adalah pulau kecil yang tidak berpenghuni terletak di sebelah utara Pulau Karimunjawa (BTNKJ, 2018). Kedua pulau tersebut memiliki beberapa ekosistem, salah satunya adalah ekosistem padang lamun. Echinodermata merupakan salah satu biota yang hidup di ekosistem lamun, dan berperan sebagai salah satu komponen dalam rantai makanan, pemakan sampah organik dan hewan kecil lainnya (Erlangga et al., 2018). Perbedaan kedua pulau tersebut diduga akan mempengaruhi kondisi biota yang hidup didalamnya termasuk Echinodermata yang hidup pada habitat ekosistem padang lamun. Menurut Rustam et al., (2019), kondisi ekosistem padang lamun di Pulau Kemujan kurang sehat dan memiliki daun dalam kondisi rusak. Sedangkan di Pulau Bengkoang memiliki kondisi lamun yang sehat dan masih alami.

Penelitian mengenai struktur komunitas Echinodermata di ekosistem padang lamun ini akan dilakukan di Pulau Kemujan dan Pulau Bengkoang dengan tujuan mengetahui kelimpahan, keanekaragaman, keseragaman dan dominansi Echinodermata serta mengetahui kerapatan lamun.

\section{MATERI DAN METODE}

Materi penelitian ini adalah Echinodermata yang ditemukan di perairan Pulau Kemujan dan Pulau Bengkoang Karimunjawa. Metode dalam penelitian ini yaitu metode deskriptif. Menurut Supriharyono et al., (2017) metode penelitian deskriptif merupakan penelitian yang bertujuan untuk memberikan gambaran dari variable penelitian Lokasi penelitian ditentukan berdasarkan aktivitas manusia dan kondisi lamun. Pengambilan data Echinodermata dilakukan di 2 lokasi yaitu Pulau Kemujan dan Pulau Bengkoang pada transek kuadran yang sama dengan lamun, menggunakan metode Seagress Watch. Masing masing lokasi terdapat 3 titik sekaligus sebagai pengulangan, dengan jarak antar titik 25 meter sejajar garis pantai. Penarikan transek kuadran berukuran $50 \times 50 \mathrm{~cm}^{2}$ dilakukan ketika pertama kali ditemukannya lamun, tegak lurus kearah laut lepas sepanjang $50 \mathrm{~m}$. Transek kuadran diletakkan dimulai dari titik, lalu ke arah 1 meter dari kanan dan 1 meter dari kiri, dengan jarak antar kuadran $5 \mathrm{~m}$. Echinodermata yang ditemukan dalam tansek kuadran di dokumentasikan menggunakan kamera digital underwater. Sampel Echinodermata dibawa ke laboratorium untuk diidentifikasi. Pengambilan parameter lingkungan meliputi suhu, kedalaman, salinitas, $\mathrm{pH}$, DO dilakukan secara insitu yaitu pengambilan secara langsung di lapangan.

Analisis data Echunodermata terdiri dari Kelimpahan, Indeks Keanekaragaman, Indeks Keseragaman, dan Indeks Dominansi. Kelimpahan Echinodermata dihitung menggunakan rumus indeks Shannon Wienner yaitu jumlah individu $(\mathrm{N})$ dibagi dengan luas daerah pengamatan $\mathrm{m}^{2}(\mathrm{~A})$ (Sulphayrin et al., 2018).

Indeks Keanekaragaman $\left(\mathrm{H}^{\prime}\right)$ dihitung menggunakan rumus "Shannon index of diversity" (Odum, 1971). Nilai indeks keanekaragaman apabila $H^{\prime}<1$ memiliki Keanekaragaman rendah, $1 \leq$ $\mathrm{H}^{\prime} \geq 3$ kategori keanekaragaman sedang dan nilai $\mathrm{H}^{\prime}>3$ kategori keanekaragaman tinggi. Indeks keseragaman dihitung dengan cara membandingkan indeks keanekaragaman dengan nilai maksimumnya, menggunakan rumus Indeks Equitabilitas (E) (Sulphayrin et al., 2018). Indeks keseragaman berkisar antara 0-1. Bila indeks keseragaman kurang dari 0,4 maka ekosistem tersebut berada dalam kondisi tertekan dan mempunyai keseragaman rendah. Jika indeks keseragaman antara 0,4 sampai 0,6 maka ekosistem tersebut pada kondisi kurang stabil dan mempunyai keseragaman sedang. Jika indeks keseragaman lebih dari 0,6 maka ekosistem tersebut dalam kondisi stabil dan mempunyai keseragaman tinggi (Fachrul, 2012). Indeks Dominansi dapat dinyatakan dalam indeks dominansi Simpson. Nilai indeks dominansi berkisar antara 0-1. Semakin besar nilai indeks semakin besar kecenderungan salah satu jenis yang mendominansi populasi. Sedangkan nilai dominansi yang rendah menyatakan konsentrasi dominasi yang tinggi, artinya terdapat jenis yang mendominansi dalam komunitas tersebut, karena 
jika ada jenis yang mendominasi maka keseimbangan komunitas akan menjadi tidak stabil dan akan mempengaruhi keanekaragaman dan keseragaman (Odum, 1993). Kerapatan Jenis (Di) lamun dihitung dengan rumus (Syari, 2005) dimana jumlah individu (tegakan) dalam transek kuadrat dibagi dengan luas transek kuadrat $\mathrm{m}^{2}$.

\section{HASIL DAN PEMBAHASAN}

Hasil penelitian yang dilakukan di lokasi 1 Pulau Kemujan Karimunjawa, ditemukan 2 Kelas, yaitu Holothuroidea dan Echinoidea. Kelas Holothuroidea ditemukan spesies Holothuria atra berjumlah 5, untuk Kelas Echnoidea spesies Laganum laganum berjumlah 2. Sedangkan di Pulau Bengkoang ditemukan 3 Kelas meliputi Holothuroidea, Asteroidea, Echinoidea. Untuk Kelas Holothuroidea ditemukan 14 spesies Holothuria atra dan 1 spesies Stichopus horrens. Kelas Asteroidea ditemukan 1 spesies Linckia leavigata, 2 spesies Protoreaster nodosus dan 1 spesies Nardoa tuberculata. Sedangkan untuk Kelas Echinoidea ditemukan 1 spesies Echinarachnius parma dan 1 spesies Laganum laganum yang tersaji dalam Tabel 1.

Hasil kelimpahan Echinodermata di Pulau Kemujan dari Kelas Holothuroidea spesies Holothuria atra $20 \mathrm{ind} / \mathrm{m}^{2}$ dan Kelas Echinoidea spesies Laganum laganum $4 \mathrm{ind} / \mathrm{m}^{2}$. Hasil penelitian di Pulau Bengkoang diperoleh kelimpahan Echinodermata Kelas Holothuroidea spesies Holothuria atra sebanyak $56 \mathrm{ind} / \mathrm{m}^{2}$, Stichopus horrens (4 ind $\left./ \mathrm{m}^{2}\right)$. Linckia leavigata, Nardoa tuberculata, Echinarachnius parma, dan Laganum laganum memiliki nilai kelimpahan yang sama yaitu $4 \mathrm{ind} / \mathrm{m}^{2}$. Sedangkan kelimpahan Protoreaster nodosus sebesar $8 \mathrm{ind} / \mathrm{m}^{2}$.

Pulau Kemujan memiliki total kelimpahan sedikit dibandingkan kelimpahan di Pulau Bengkoang. Penyebaran paling banyak ditemukan di substrat pasir yaitu jenis teripang Holothuria atra. Menurut Elfidasari et al.,(2012) Holothuria atra memiliki kemampuan membenamkan diri untuk menghindari cahaya matahari, dengan cara menempeli tubuhnya dengan butiran pasir halus, sehingga akan memantulkan cahaya dan membuat suhu tubuhnya lebih rendah. Untuk Kelas Echinoidea dan Asteroidea sedikit ditemukan di ekosistem lamun yang bersubstrat pasir disebabkan karena Asteroidea dan Echinoidea berperan sebagai penyeimbang populasi, terutama karang, yang ada di perairan tersebut (Nybakken, 1982). Perbedaan kelimpahan kedua pulau tersebut disebabkan karena di Pulau Kemujan terdapat kegiatan aktivitas manusia seperti perikanan laut, potensi perikanan tangkap, budidaya rumput laut, dan wisata bahari yang diduga akan mempengaruhi kelimpahan Echinodermata, mengganggu habitat Echinodermata yaitu ekosistem padang lamun sebagai tempat pemijahan, perlindungan dan mencari makan akan terganggu karena aktivitas manusia tersebut. Sedangkan Pulau Bengkoang adalah pulau yang tidak berpenghuni, dengan kondisi perairan masih sangat baik bagi habitat organisme laut termasuk Echinodermata, sehingga tidak akan merasa terganggu. Hasil penelitian menunjukan bahwa Echinodermata menyukai habitat dengan perairan yang jernih dan aliran air relatif tenang. Menurut Katili, (2011) selain perbedaan habitat, penyebaran Echinodermata juga dipengaruhi oleh kelimpahan makanan yang tersedia berupa plankton dan detritus. Hasil perhitungan indeks keanekaragaman, indeks keseragaman dan indeks dominansi Echinodermata di Pulau Kemujan dan Pulau Bengkoang dapat disajikan pada Tabel 2.

Indeks keanekaragaman ( $\left.H^{\prime}\right)$ di Pulau Kemujan 0,025, di Pulau Bengkoang 1,048. Nilai indeks keanekaragaman Shannon Wienner bahwa $H^{\prime}<1$ menunujukkan keanekaragaman rendah, $1 \leq \mathrm{H}^{\prime} \geq 3$ keanekaragaman sedang dan $\mathrm{H}^{\prime}>3$ keanekaragaman tinggi. Berdasarkan nilai tersebut di Pulau Kemujan tergolong rendah karena jumlah individu Echinodermata di tempat tersebut sedikit dan sangat tidak merata. Menurut Wahab et al., (2018), keanekaragaman jenis dipengaruhi oleh pembagian atau penyebaran individu dari tiap jenisnya, karena suatu komunitas walaupun banyak jenis, tetapi bila penyebaran individunya tidak merata, maka keanekaragaman jenisnya rendah. Hal ini menyebabkan kestabilan dalam komunitas yang terjadi berada pada kondisi kurang normal. Sedangkan di Pulau Bengkoang keanekaragaman tergolong sedang dimana penyebaran Echinodermata tiap individu kurang merata, diduga karena masing-masing individu memiliki pola adaptasi yang berbeda dan kondisi dari lingkungan tersebut. Menurut Sinyo dan Idris (2013), indeks keanekaragaman tergantung pada variasi jumlah spesies yang terdapat dalam suatu habitat, serta ditentukan oleh jumlah individu dari masing-masing spesies sehingga jumlah individu sangat menentukan indeks keanekaragaman. 
Tabel 1. Komposisi Spesies Echinodermata yang di temukan di Pulau Kemujan dan Pulau Bengkoang Karimunjawa Jepara Jawa Tengah

\begin{tabular}{|c|c|c|c|c|c|c|c|c|}
\hline \multirow{3}{*}{ No. } & \multirow{3}{*}{ Kelas } & \multirow{3}{*}{ Spesies } & \multicolumn{6}{|c|}{ Lokasi } \\
\hline & & & \multicolumn{3}{|c|}{ Pulau Kemujan } & \multicolumn{3}{|c|}{ Pulau Bengkoang } \\
\hline & & & 1 & 2 & 3 & 1 & 2 & 3 \\
\hline \multirow[t]{2}{*}{1.} & Holothuroidea & Holothuria atra & + & + & + & + & + & + \\
\hline & & Stichopus horrens & - & - & - & + & - & - \\
\hline \multirow[t]{3}{*}{2.} & Asteroidea & Linckia Leavigata & - & - & - & + & - & - \\
\hline & & Protoreaster nodosus & - & - & - & + & - & - \\
\hline & & Nordoa tuberculata & - & - & - & - & + & - \\
\hline \multirow[t]{3}{*}{3.} & Echinoidea & Echinarachnius Parma & - & - & - & - & - & + \\
\hline & & Laganum laganum & + & + & - & - & - & + \\
\hline & Jumlah & & 2 & 2 & 1 & 4 & 2 & 3 \\
\hline
\end{tabular}

Keterangan:+ = Ada; - = Tidak ada

Tabel 2. Indeks Keanekaragaman ( $\left.\mathrm{H}^{\prime}\right)$, Indeks Keseragaman Echinodermata Di Pulau Kemujan dan Pulau Bengkoang

(E), Indeks Dominansi (C)

\begin{tabular}{cccl}
\hline Lokasi & $\mathrm{H}^{\prime}$ & $\mathrm{E}$ & $\mathrm{C}$ \\
\hline Pulau Kemujan & 0,025 & 0,030 & 0,296 \\
Pulau Bengkoang & 1,048 & 0,793 & 0,066 \\
\hline
\end{tabular}

Indeks keseragaman (E) di Pulau Kemujan 0,030 sedangkan di Pulau Bengkoang 0,793 Berdasarkan nilai indeks keseragaman (E) Pulau Kemujan tergolong rendah sedangkan Pulau Bengkoang tergolong tinggi. Menurut Supono dan Arbi, (2010) suatu komunitas bisa dikatakan stabil bila mempunyai nilai indeks keseragaman jenis mendekati angka 1 , dan sebaliknya dikatakan tidak stabil jika mempunyai nilai indeks keseragaman jenis yang mendekati angka 0 . Indeks keseragaman di Pulau Kemujan tergolong rendah serta dalam kondisi tertekan disebabkan oleh banyaknya aktivitas penduduk seperti lalu lintas kapal di dekat dermaga, aktivitas perikanan tangkap diduga akan merusak ekosistem lamun yang menjadi habitat bagi Echinodermata.

Nilai dominansi di Pulau Kemujan dan Pulau Bengkoang tergolong rendah artinya tidak ada spesies yang mendominansi di kedua pulau tersebut, karena jika ada jenis yang mendominasi maka keseimbangan komunitas akan menjadi tidak stabil dan akan mempengaruhi keanekaragaman dan keseragaman (Odum, 1993).

Lamun yang ditemukan di Pulau Kemujan yaitu Enhalus acoroides, Thalassia hemprichii, dan Cymodocea serulata, sedangkan di Pulau Bengkoang meliputi Enhalus acoroides, Thalassia hemprichii, Halophila ovalis, Cymodocea rotundata dan Cymodocea serulata. Kerapatan total lamun tertinggi terdapat di Pulau Bengkoang yaitu 164,09 ind $/ \mathrm{m}^{2}$ dapat dilihat pada Gambar 1.3

Echinodermata lebih banyak ditemukan jenisnya di habitat lamun dengan kerapatan tinggi yaitu di Pulau Bengkoang. Perbedaan nilai kerapatan lamun di Pulau Kemujan dan Pulau Bengkoang disebabkan karena karakteristik substrat yang berbeda antar pulau, sebaran pertumbuhan lamun yang tidak tersebar secara merata. Kondisi lingkungan Pulau Bengkoang termasuk zona alami, sehingga kondisi lamun di pulau tersebut masih tergolong baik. Sedangkan Pulau Kemujan merupakan zona pemukiman menyebabkan Echinodermata yang ditemukan lebih sedikit dengan kondisi lamun yang kurang baik dan kurang sehat. Lamun yang banyak ditemukan yaitu Thalassia hemprichii dengan kondisi substrat pasir dengan sedikit lumpur. Menurut Tomascik et al., (1997), jenis Thalassia hemprichii sering ditemukan melimpah pada daerah yang memiliki substrat dasar pasir lanau (lumpur), pasir kasar, dan pecahan karang karena secara morfologi jenis ini memiliki rimpang yang tebal dan kokoh sehingga memungkinkan untuk tumbuh pada substrat yang bervariasi. Sedangkan di Pulau Bengkoang, lamun banyak ditemukan jenis Cymodocea rotundata. Cymodocea rotundata mudah beradaptasi dengan lingkungan. 
Berdasarkan penelitian Riniatsih dan Endrawati (2013) bahwa tingkat kehidupan transplantasi lamun jenis Cymodocea rotundata sebesar 100\% menunjukan bahwa lamun jenis ini merupakan lamun yang mudah untuk beradaptasi dan dapat tumbuh pada berbagai kondisi lingkungan.

Faktor lingkungan sangat penting bagi kehidupan Echinodermata, meliputi suhu, salinitas, oksigen terlarut, $\mathrm{pH}$, kedalaman, substrat dan kandungan bahan organik. Hasil suhu di Pulau Kemujan $30^{\circ} \mathrm{C}$, di Pulau Bengkoang $32,9^{\circ} \mathrm{C}$. Menurut Iswanti et al.,(2012), suhu lingkungan untuk organisme laut berkisar antara $28-31^{\circ} \mathrm{C}$. Suhu di Pulau Bengkoang tidak berada dalam kisaran tersebut diduga karena pengambilan dilakukan pada siang hari sehingga suhunya lebih tinggi, tetapi masih dapat di toleransi oleh Echinodermata. Hasil pengukuran salinitas, oksigen terlarut (DO), dan pH dilihat pada Tabel 4 juga memiliki nilai yang sesuai untuk kehidupan Echinodermata.

Kedalaman berpengaruh pada pola penyebaran Echinodermata seperti jumlah jenis, jumlah individu dan biomasa (Sulardiono et al., 2016). Tipe substrat juga berpengaruh terhadap kehidupan Echinodermata. Pulau Kemujan memiliki substrat pasir bercampur lumpur yang sangat keruh, sedangkan di Pulau Bengkoang memiliki substrat pasir halus yang ditumbuhi algae. Menurut Ruswahyuni dan Suryanti (2014), Jenis sedimen berkaitan erat dengan kandungan oksigen dan ketersediaan nutrient dalam sedimen. Sedimen yang berpasir, memiliki kandungan oksigen relatif lebih besar daripada sedimen halus, karena pada sedimen berpasir terdapat poripori udara yang memungkinkan terjadinya percampuran yang lebih intensif dengan air di atasnya. Kandungan bahan organik sangat mempengaruhi habitat biota laut, karena bahan organik merupakan makanan bagi biota laut, hal ini dinyatakan oleh Novianti et al., (2016), hewan benthos seperti Echinodermata erat kaitanya dengan tersedianya bahan organik yang terkandung dalam substrat, karena bahan organik merupakan sumber nutrien bagi biota yang pada umunya terdapat pada substrat dasar.

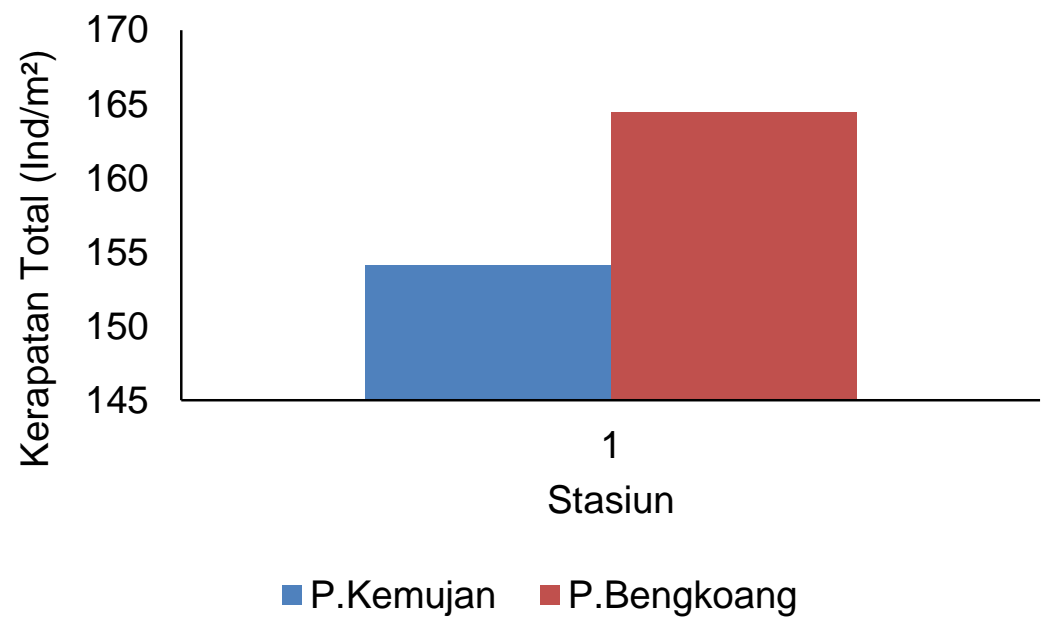

Gambar 1. Kerapatan (ind/m²) Lamun di Pulau Kemujan dan Pulau Bengkoang Karimunjawa

\section{KESIMPULAN}

Hasil indeks keanekaragaman $\left(H^{\prime}\right)$ di Pulau Kemujuan tergolong rendah yaitu 0,025 sedangkan Pulau Bengkoang tergolong sedang $(1,048)$. Nilai indeks keseragaman (E) Pulau Kemujan rendah $(0,030)$ dan Pulau Bengkoang tergolong tinggi $(0,793)$ serta tidak ada yang mendominansi di kedua pulau tersebut.

\section{UCAPAN TERIMAKASIH}

Artikel ini merupakan bagian dari penelitian yang berjudul "Struktur Komunitas Echinodermata Pada Ekosistem Padang Lamun di Pulau Kemujan dan Pulau Bengkoang Taman Nasional Karimunjawa Jepara, Jawa Tengah", untuk memperoleh gelar sarjana Strata 1 pada Departemen IImu Kelautan Fakultas Perikanan dan IImu Kelautan Universitas Diponegoro 


\section{DAFTAR PUSTAKA}

Balai Taman Nasional KarimunJawa. 2018. Statistik Balai Taman Nasional Karimunjawa Tahun 2018. Semarang.

Elfidasari, D., Noriko, N., Wulandari, N. \& Perdana, A.T. 2012. Identifikasi Jenis Teripang Genus Holothuria Asal Perairan Sekitar Kepulauan Seribu Berdasarkan Perbedaan Morfologi. Jurnal Al-Azhar Indonesia Seri Sains dan Teknologi. 1 (3):140-146.

Erlangga, Y., Rahimi, S.A.E \& Devira, C.N. 2018. Struktur Komunitas Echinodermata Di Perairan Pantai Gapang, Desa Iboih, Kecamatan Sukakarya, Sabang. Jurnal IImiah Mahasiswa Kelautan Dan Perikanan Unsyiah, 3(1):92-101.

Fachrul, M.F., 2012. Metode Sampling Bioekologi. Bumi Aksara Jakarta.

Iswanti, S., Ngabekti \& Martut. 2012. Distribusi dan Keanekaragaman Jenis Makrozoobentos di Sungai Damar Desa Weleri Kabupaten Kendal. Unnes Journal of Life Science, 1(2): 87-88.

Katili, A.S. 2011. Struktur Komunitas Echinodermata Pada Zona Intertidal Di Gorontalo. Jurnal Penelitian Dan Pendidikan., 8(1):51-55.

Keputusan Menteri Negara Lingkungan Hidup Nomor: 51 Tahun 2004 Tentang Baku Mutu Air Laut.

Novianti, M., Rusyana, A. \& Romansyah, R. 2016. Keanekaragaman Jenis Echinodermata Pada Berbagai Macam Substrat Pasir, Lamun Dan Karang di Perairan Pantai Sindangkertacipatujah Tasikmalaya. Jurnal Pendidikan Biologi, 4(1):19-25.

Riniatsih, I. \& Endrawati, H. 2013. Pertumbuhan Lamun Hasil Transplantasi Jenis Cymodocea rotundata di Padang Lamun Teluk Awur Jepara. Buletin Oseanografi Marina, 2(1):24-30.

Rustam, A., Ningsih, Y.P.R., Suryono D.D., Daulat, A. \& Salim, H.L. 2019. Dinamika Struktur Komunitas Lamun Perairan Kepulauan Karimunjawa, Kabupaten Jepara. Jurnal Kelautan Nasional, 14(3):179-190.

Ruswahyuni \& Suryanti. 2014. Perbedaan Kelimpahan Bulu Babi (Echinoidea) Pada Ekosistem Karang Dan Lamun Di Pancuran Belakang, Karimunjawa Jepara. Jurnal Saintek Perikanan., 10(1): 62-67.

Sinyo, Y. \& Idris, J. 2013. Studi Kepadatan dan Keanekaragaman Jenis Organisme Bentos Pada Daerah Padang Lamun di Perairan Pantai Kelurahan Kastela Kecamatan Pulau Ternate. Jurnal Bioedukasi, 2(1):154-162.

Sulardiono,B., U.R.Sofiana dan M. Nitisupardjo. 2016. Hubungan Kandungan Bahan Organik Sedimen Dengan Kelimpahan Infauna Pada Kerapatan Lamun yang Berbeda Di Pantai Bandengan Jepara. Journal of Maquares, 5(3):135-141.

Sulphayrin, Ola, L.O.L. \& Arami, H. 2018. Komposisi dan Jenis Makrozoobenthos (Infauna) Berdasarkan Ketebalan Substrat Pada Ekosistem Lamun Di Perairan Nambo Sulawesi Tenggara. Jurnal Manajemen Sumber Daya Perairan, 3(4):343-352.

Supono, \& Arbi, U.Y. 2010. Struktur Komunitas Ekinodermata di Padang Lamun Perairan Kema, Sulawesi Utara. Oseanologi dan Limnologi di Indonesia, 36(3):329-341.

Supriharyono., Setyowati, D.A. \& Taufani, W.T. 2017. Bioekologi Bintang Laut (Asteroidea) Di Perairan Pulau Menjangan Kecil, Kepulauan Karimunjawa. Journal of Maquares., 6(4):393400.

Syari, I.A. 2005. Asosiasi Gastropoda di Ekosistem Padang Lamun. Departemen Ilmu dan Teknologi Kelautan, Fakultas Perikanan dan IImu Kelautan, IPB, Bogor.

Wahab, I., Kawaroe, M. \& Madduppa, H.. 2018. Perbandingan Kelimpahan Makrozoobentos Di Ekosistem Lamun Pada Saat Bulan Purnama Dan Perbani di Pulau Panggang Kepulauan Seribu Jakarta. Jurnal IImu Dan Teknologi Kelautan Tropis, 10(1):217-229. 